Supplement of

\title{
Bedload transport measurements with impact plate geophones in two Austrian mountain streams (Fischbach and Ruetz): system calibration, grain size estimation, and environmental signal pick-up
}

Dieter Rickenmann and Bruno Fritschi

Correspondence to: Dieter Rickenmann (dieter.rickenmann@wsl.ch)

The copyright of individual parts of the supplement might differ from the CC BY 3.0 License. 
SCHNITT 2 - 2

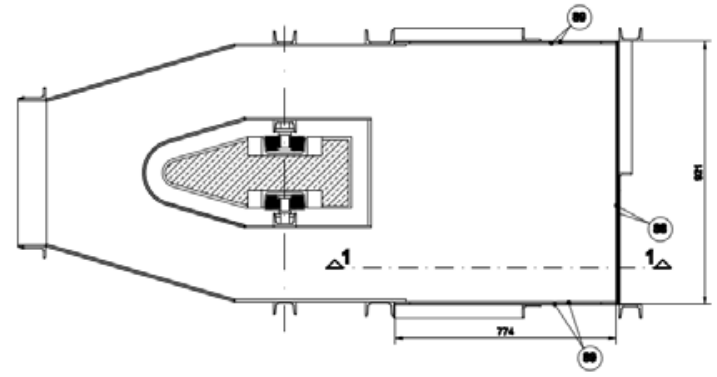

(a)

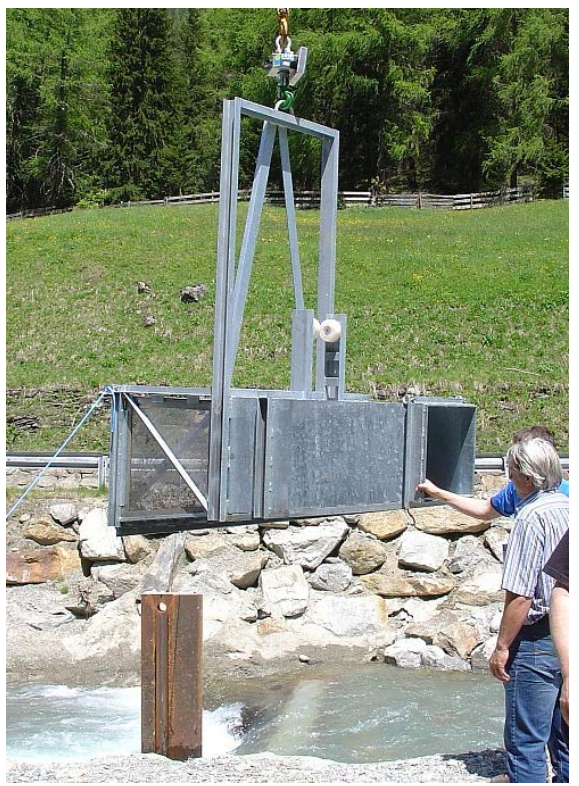

(c)

(d)

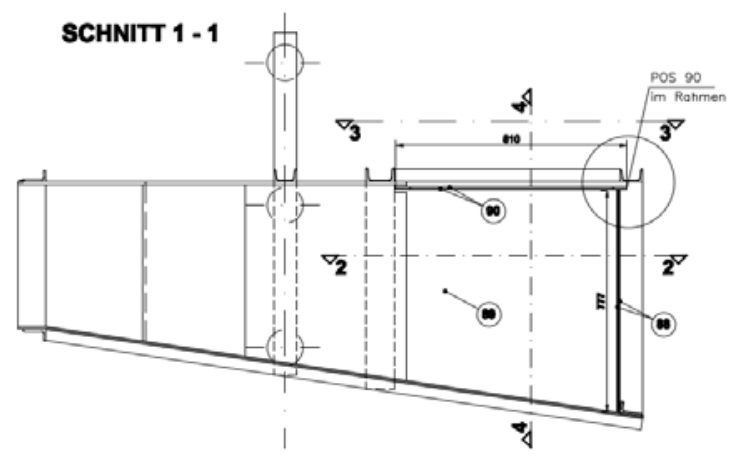

(b)

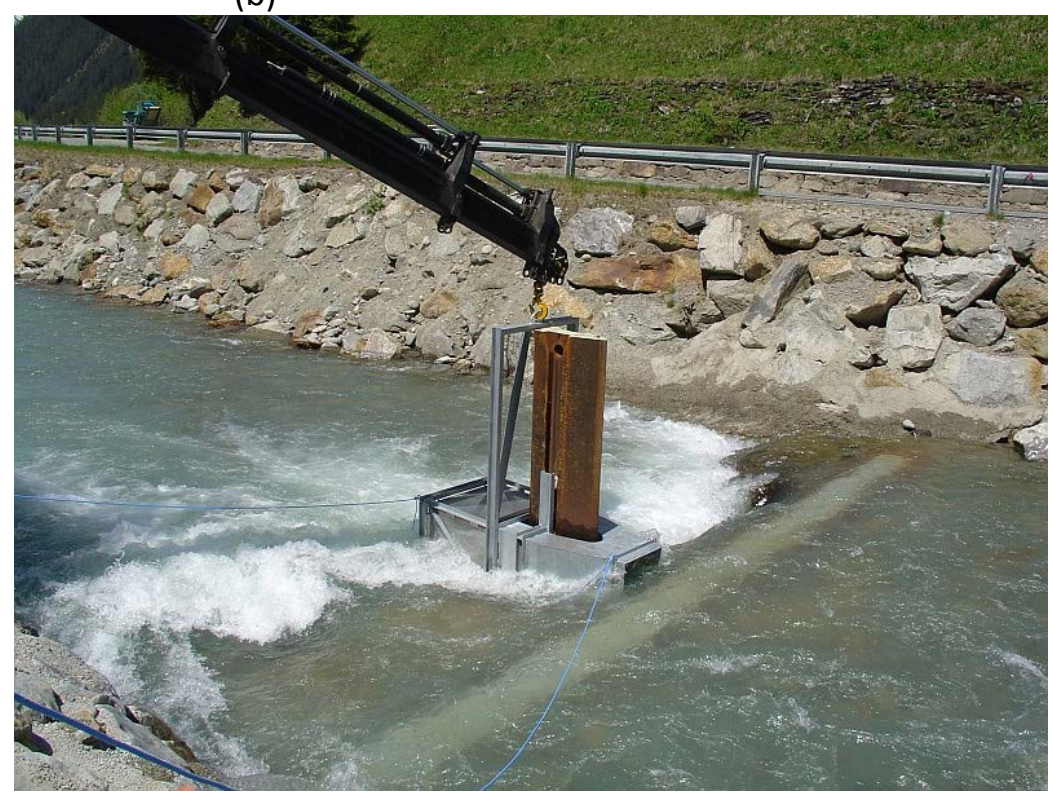

Figure S1. Basket sampler as designed and used by TIWAG to collect bedload samples downstream of the geophone plate where there is a steel-concrete pillar to guide the position of the sampler during the calibration measurements. (a) top view, upstream side on left; (b) side view, upstream side on left; (c) photo of sampler looking from upstream; (d) photo of sampler placed downstream of a geophone plate during a calibration measurement (i.e. direct bedload sampling). 


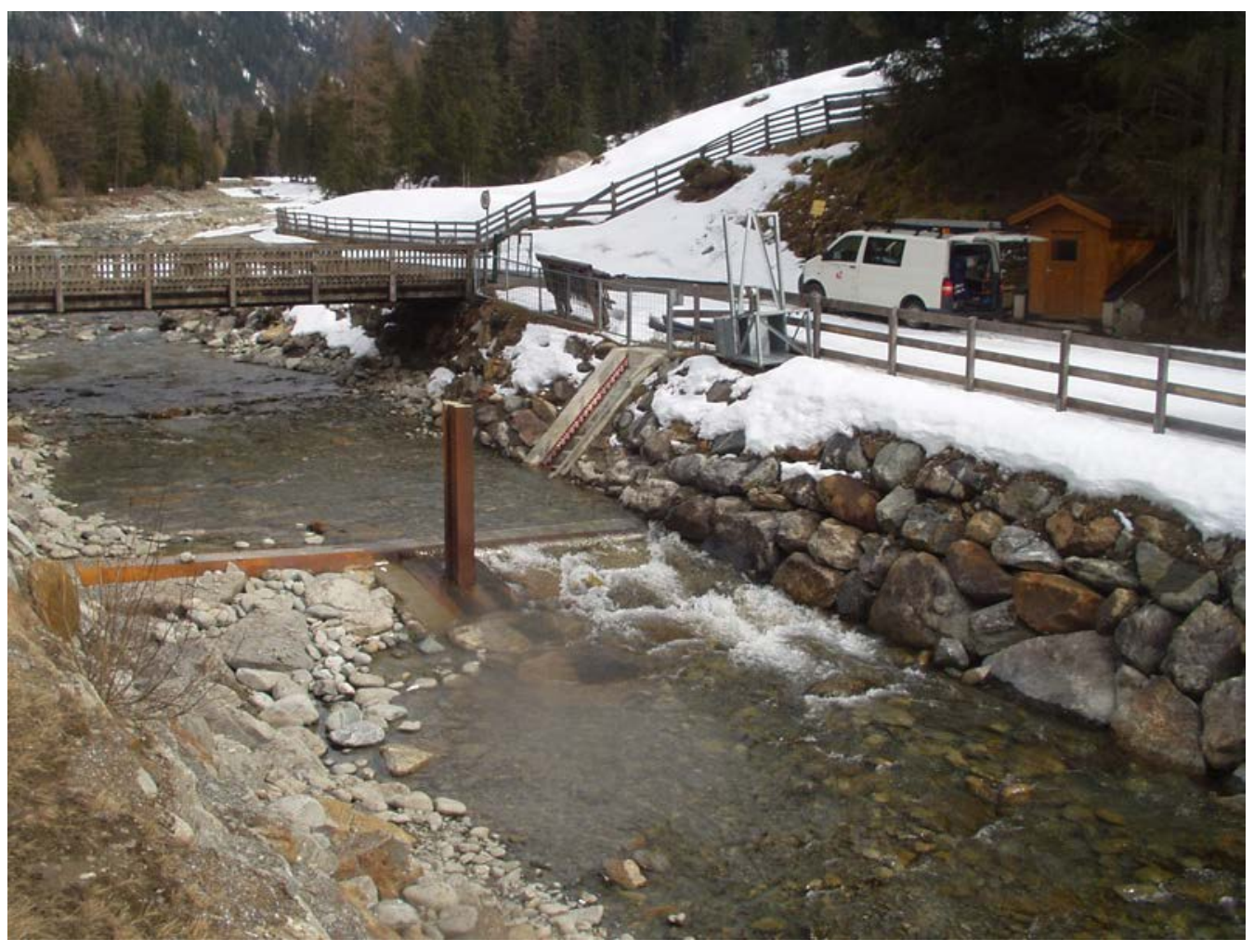

Figure S2. Geophone measuring cross-section at the Fischbach in March 2013, view looking upstream. Note that only about half the width of the sill with the steel plate is submerged under water. Base-flow during this period is approximately $1 \mathrm{~m}^{3} \mathrm{~s}^{-1}$. (Photo Hydrographic Service of Tyrol.) 

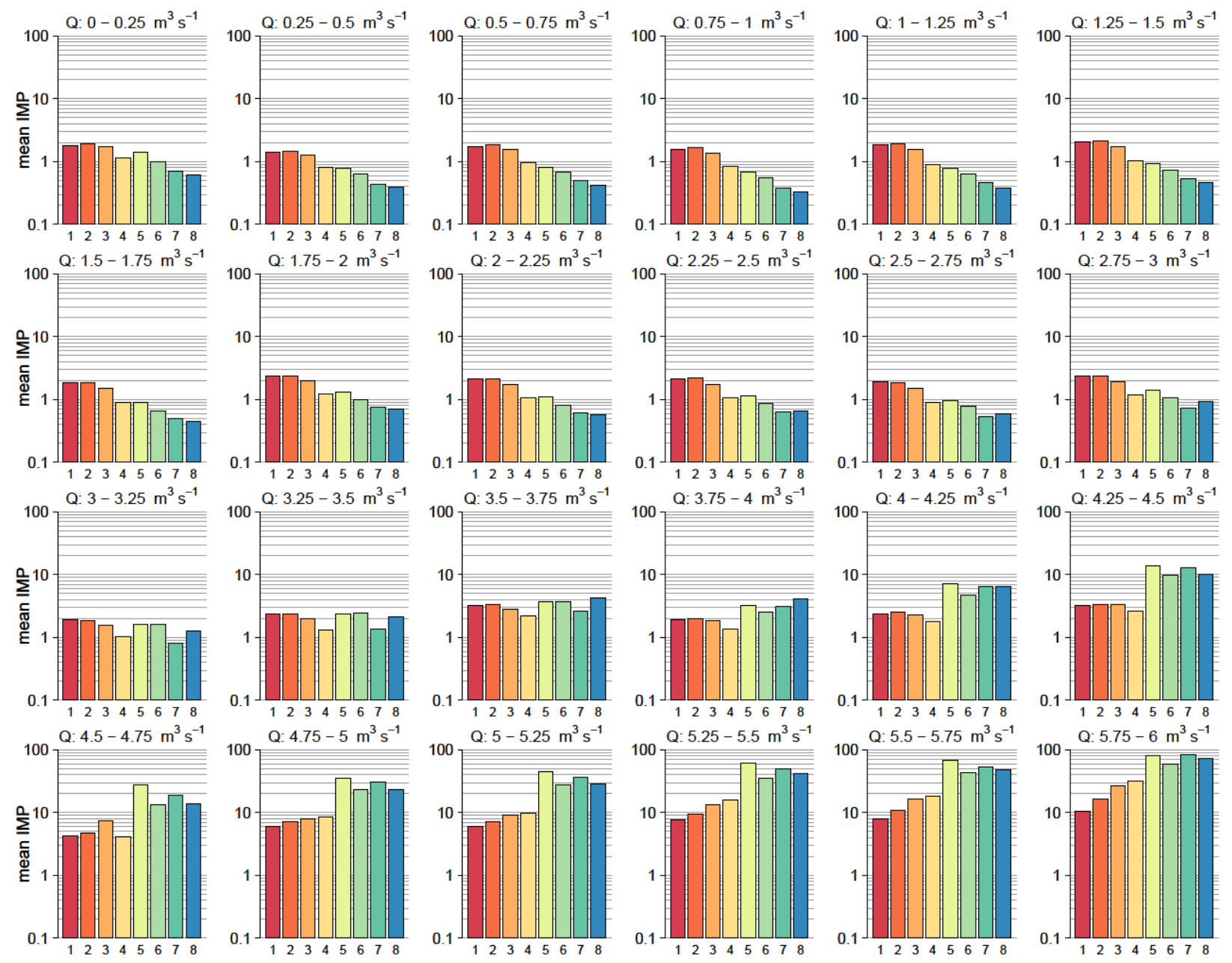

Figure S3. Fischbach: Arithmetic mean of geophone impulses per $15 \mathrm{~min}$ for each of the 8 plates (ordinates), averaged over the period 2008-2013 and including zero values, for discharge Q classes of width of $0.25 \mathrm{~m}^{3} \mathrm{~s}^{-1}$, for discharges up to $6 \mathrm{~m}^{3} \mathrm{~s}^{-1}$. 

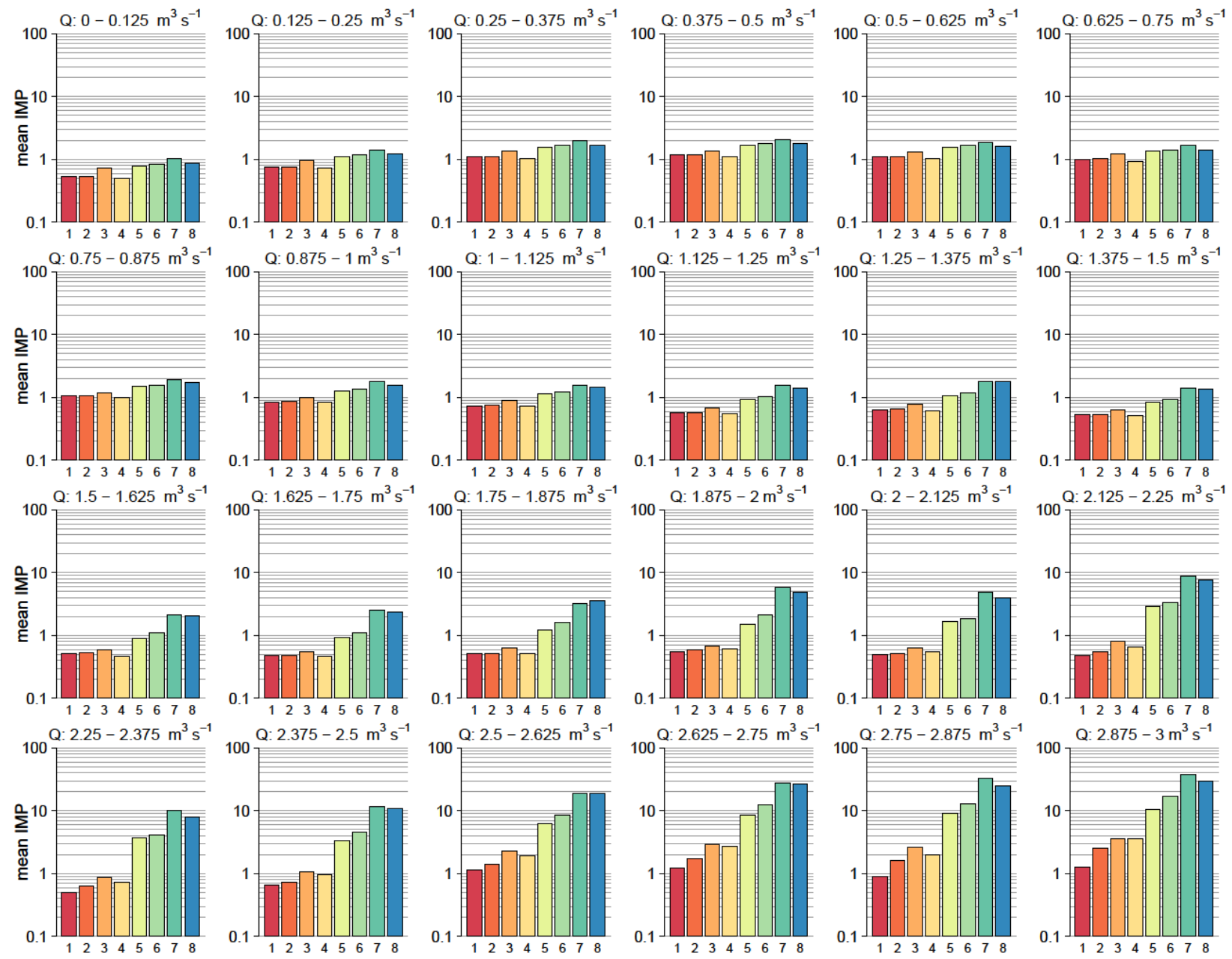

Figure S4. Ruetz: Arithmetic mean of geophone impulses per $15 \mathrm{~min}$ for each of the 8 plates (ordinates), averaged over the period 2008-2013 and including zero values, for discharge Q classes of width of $0.25 \mathrm{~m}^{3} \mathrm{~s}^{-1}$, for discharges up to $3 \mathrm{~m}^{3} \mathrm{~s}^{-1}$. 


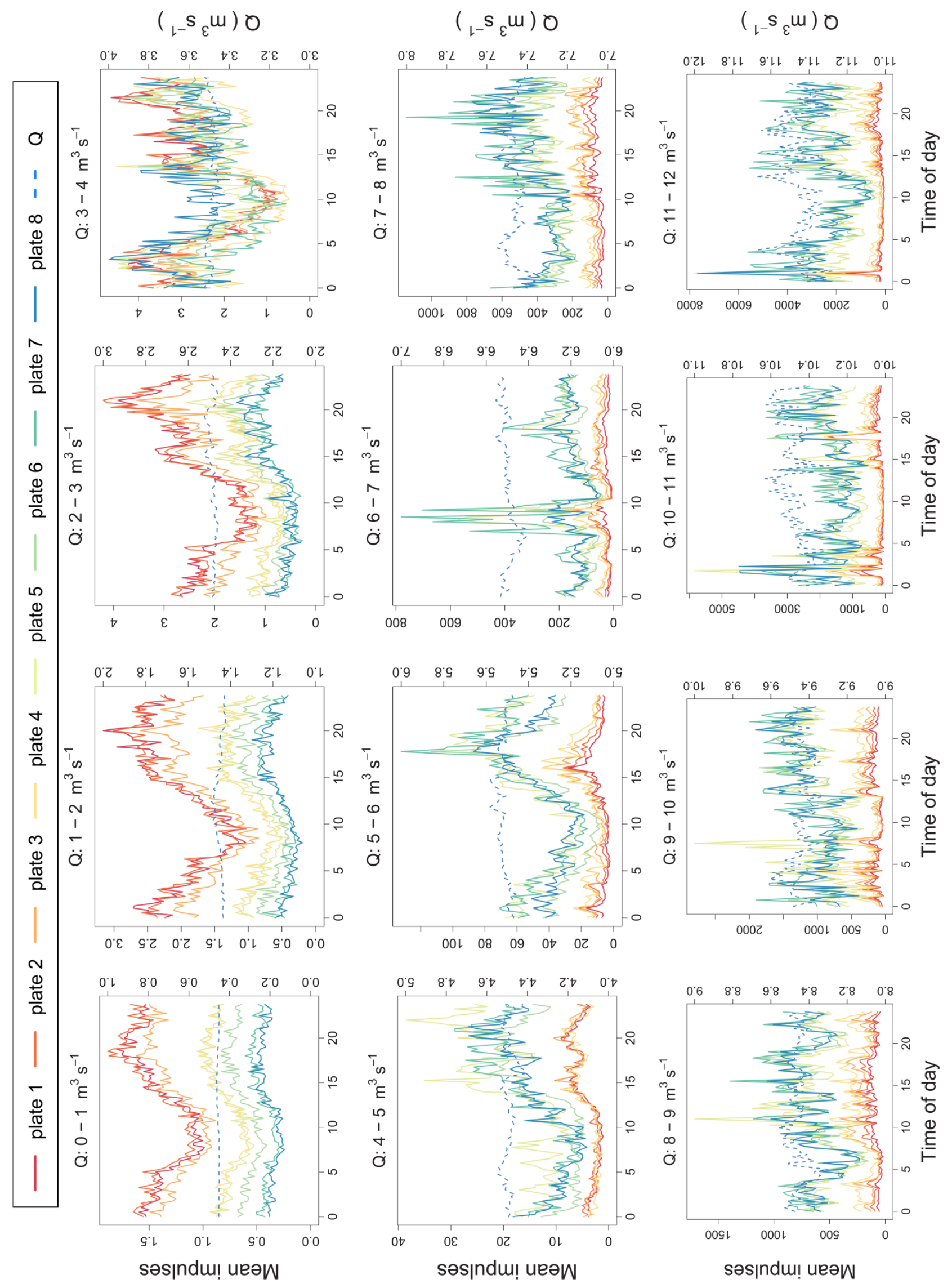

Figure S5. Fischbach: Mean of recorded impulses (mean IMP) for each of the 8 plates, and mean of discharge (Q), versus time of day, averaged for the period 2008-2013 and including zero values, shown for different discharge classes of width of $1.0 \mathrm{~m}^{3} \mathrm{~s}^{-1}$, for discharges up to $12 \mathrm{~m}^{3} \mathrm{~s}^{-1}$. (Same color scheme as in Fig. 12 and Fig. S3.) 


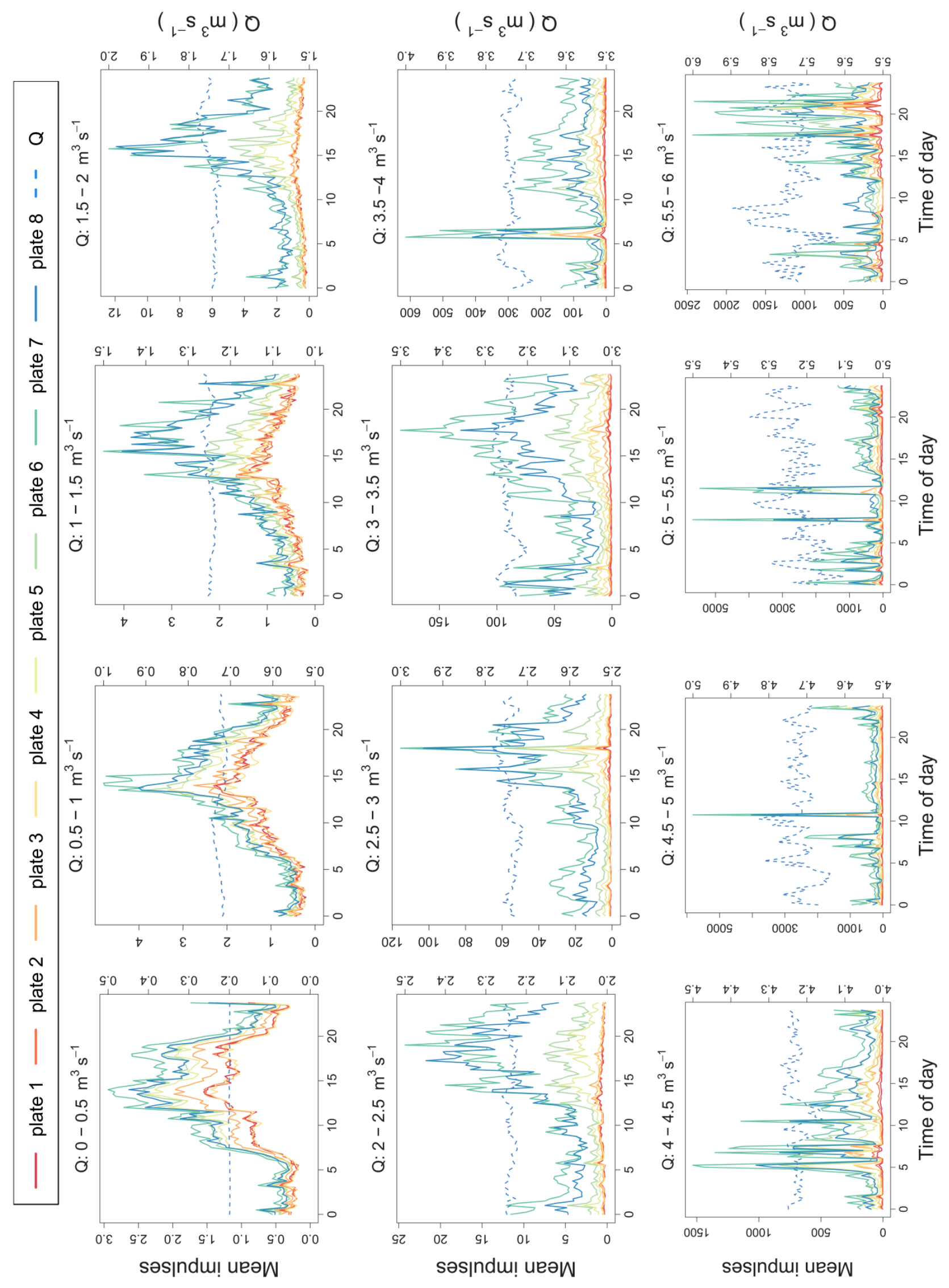

Figure S6. Ruetz: Mean of recorded impulses (mean IMP) for each of the 8 plates, and mean of discharge (Q), versus time of day, averaged for the period 2008-2013 and including zero values, shown for different discharge classes of width of $0.5 \mathrm{~m}^{3} \mathrm{~s}^{-1}$, for discharges up to $6 \mathrm{~m}^{3} \mathrm{~s}^{-1}$. . (Same color scheme as in Fig. 13 and Fig. S4.) 


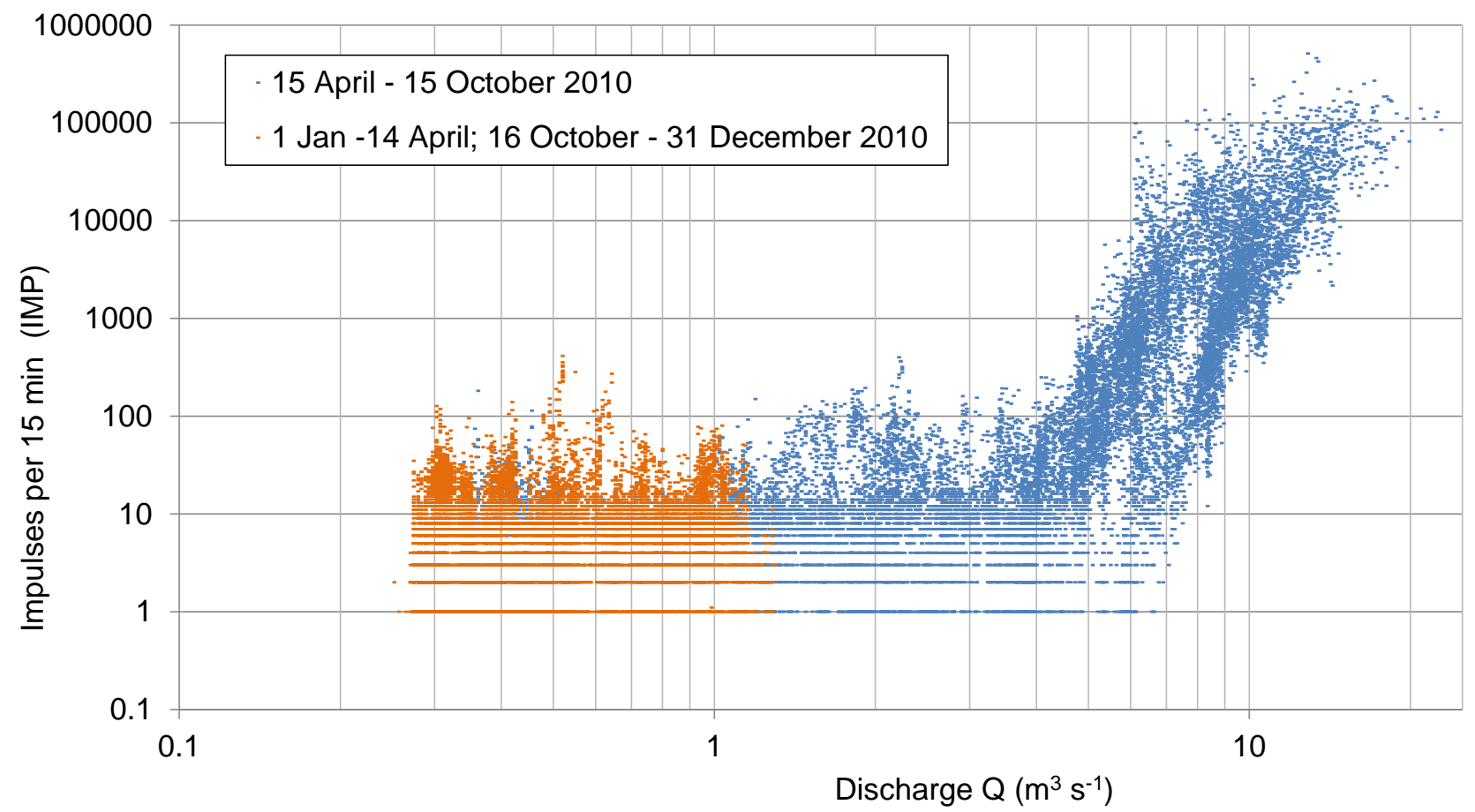

Figure S7. Fischbach: Sum of geophone impulses per 15 minute intervals (IMP) for all 8 plates versus discharge $Q$, for the entire year 2010. Discharges smaller than about $1-2 \mathrm{~m}^{3} \mathrm{~s}^{-1}$ are unlikely to produce bedload transport with particles $D$ larger than about 10 to $20 \mathrm{~mm}$. Many impulses in the range of about up to $500 I M P$ and up to $3 \mathrm{~m}^{3} \mathrm{~s}^{-1}$ are implausible and are likely due to nearby road traffic.

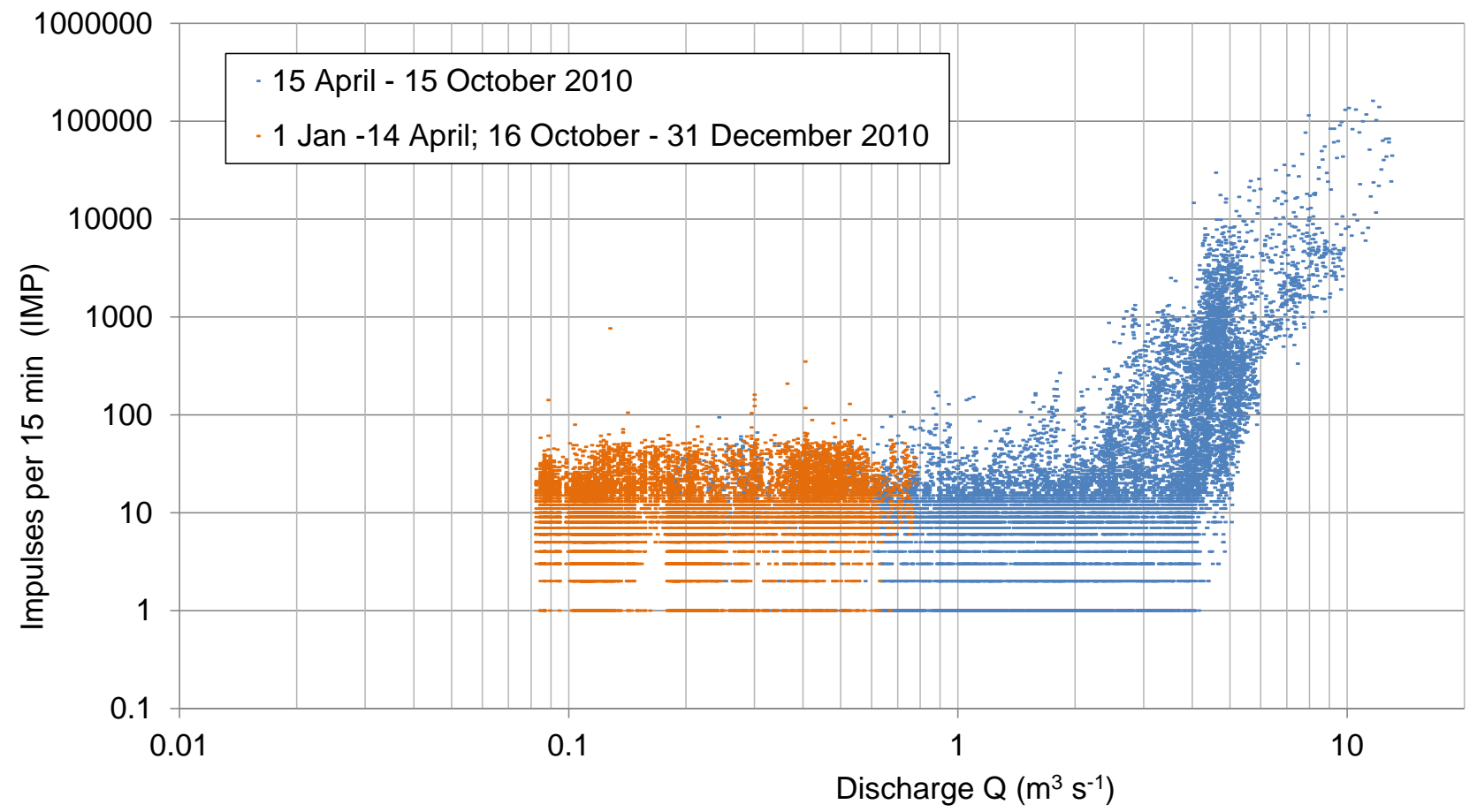

Figure S8. Ruetz: Sum of geophone impulses per 15 minute intervals (IMP) for all 8 plates versus discharge $Q$, for the entire year 2010 . Discharges smaller than about $0.5-1.0 \mathrm{~m}^{3} \mathrm{~s}^{-1}$ are unlikely to produce bedload transport with particles $D$ larger than about 10 to $20 \mathrm{~mm}$. Many impulses in the range of about up to $100 \mathrm{IMP}$ and up to $1.5 \mathrm{~m}^{3} \mathrm{~s}^{-1}$ are implausible and are likely due to nearby road traffic. 


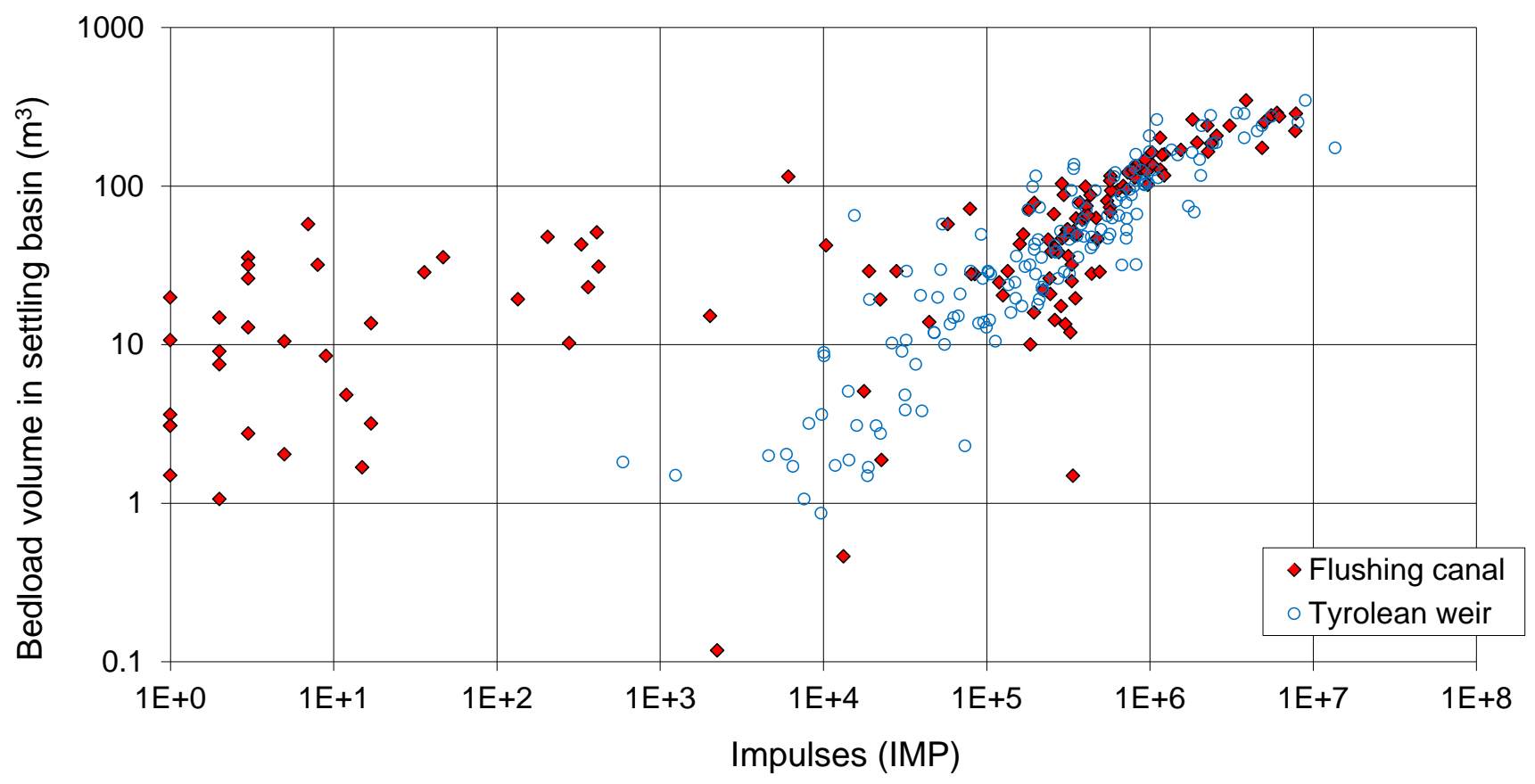

Figure S9. Data with piezoelectric bedload impact sensors (PBIS) measurements made at a water intake of the Pitzbach mountain stream in Austria during two summer periods (Rickenmann and McArdell, 2008). Impulses were counted in a similar way as for the Swiss plate geophone system. Here, impulses and bedload volumes were aggregated over daily periods. At the Tyrolean weir a total of 12 steel plates with sensors were installed, with a natural gravel-bed surface upstream of the sill of $6 \mathrm{~m}$ width. At the flushing canal, only 3 steel plates with sensors were installed, at the end of a $1.5 \mathrm{~m}$ wide concrete channel. Flushing of sediment from the settling basin occurred over relatively short time periods and thus produced high velocity flows and much higher bedload concentrations in the flow than at the (natural) approach flow to the Tyrolean weir. While a reasonably well defined calibration relation could be obtained for the measurements at the Tyrolean weir (Rickenmann and McArdell, 2008), a very large scatter can be observed for the calibration data of the flushing canal, for bedload volumes smaller than $100 \mathrm{~m}^{3}$ (see above figure). This observation indicates that there are limitations for the SPG system for extreme flow conditions. The PBIS measurements at the Pitzbach mountain stream were made by the Tyrolean Hydropower Company (TIWAG). 